\title{
The association of depression with pain-related treatment utilization in patients with multiple sclerosis
}

\author{
Kevin N. Alschuler, Ph.D. ${ }^{1}$, Mark P. Jensen, Ph.D. ${ }^{1}$, and Dawn M. Ehde, Ph.D. ${ }^{1}$ \\ ${ }^{1}$ Department of Rehabilitation Medicine, University of Washington School of Medicine, Seattle, \\ Washington
}

\section{Abstract}

Objective-To better understand the association of depression with pain treatment utilization in an MS population.

Design-Cross-sectional survey.

Setting-Community-based survey.

Participants-Convenience sample of 117 individuals with MS.

Main Outcome Measures-Participants provided demographic information, descriptive information on utilization of pain treatments, pain intensity ratings on a $0-10$ Numeric Rating Scale, and depressive symptoms on the Patient Health Questionnaire-9 (PHQ-9).

Results-Participants reporting clinical levels of depressive symptoms (PHQ-9 $\geq 10$ ) reported that they tried more pain treatments previously relative to participants with PHQ-9 $<10$; however, the two groups did not differ in the number of treatments they were currently using. Additionally, participants with PHQ-9 $\geq 10$ had more visits to providers for pain treatment relative to the group with PHQ-9 < 10. In subsequent analyses, results showed that these differences were no longer significant after controlling for level of pain intensity.

Conclusions-The results demonstrate that depression is not associated with higher pain treatment utilization. These findings support the assertion in previous studies that the mechanism by which depression impacts medical utilization is through increased appointments for nonspecific complaints, not for specific medical problems. While this suggests that treating depression may not be helpful in reducing pain treatment utilization specifically, it remains important to treat depression to reduce pain-related suffering and medical utilization more broadly.

\section{Keywords}

Pain; Depression; Medical Utilization; Multiple Sclerosis

A common secondary condition experienced by persons with multiple sclerosis (MS) is chronic pain (1), which is prevalent in 50-65\% of community samples with MS,

Corresponding Author: Kevin N. Alschuler, Tel.: 206-221-5688; fax: 206-897-4881; kalschul@uw.edu; address: Department of Rehabilitation Medicine, Box 359612, University of Washington School of Medicine, 325 Ninth Avenue, Seattle, Washington 98104 (U.S.A.).

Address Reprint Requests to: Kevin N. Alschuler, Department of Rehabilitation Medicine, Box 359612, University of Washington School of Medicine, 325 Ninth Avenue, Seattle, Washington 98104 (U.S.A.).

Financial relationships: Mark P. Jensen has received research support and/or consulting fees from RTI Health Solutions, Covidien, Endo Phamaceuticals, Bristol-Myers Squibb, Schwartz Biosciences, Analgesic Research, Depomed, Eli Lilly, Pfizer, Merck, Medtronic, and Smith \& Nephew within the past 36 months. Kevin N. Alschuler and Dawn M. Ehde declare no financial relationships. 
approximately one fourth of whom describe their pain as severe (2-4). For many persons with MS, the treatment of chronic pain can contribute to high rates of medical service utilization and subsequent higher health care costs relative to healthy controls (5). For example, one recent community-based survey of adults with MS (Ehde et al., under review) found that participants with chronic pain reported utilizing nine pain treatments on average, and sought health care for pain from a variety of sources in the previous six months, including primary care providers (62\%), specialists (47\%), and emergency departments (11\%). Not surprisingly, in a study of Australians with MS, participants with pain reported greater utilization of medical services for pain than those without pain, with nonopiod analgesics and "physical measures" [defined as "change in position, massage, change of clothes, comfortable furniture, pressure, whirlpool, transcutaneous electrical nerve stimulation (TENS), electric vibrator"] as the most commonly used treatments for pain (4).

Any of a number of variables may contribute to between-patient differences in pain treatment utilization. A likely factor is depression, which is commonly experienced by persons with MS and often co-occurs with pain. The lifetime prevalence of major depressive disorder is $50 \%$ in individuals with MS, the point-prevalence is $15-25 \%$, and clinically significant levels of depression approach 50\% at any one time (6-9). In the only known study to clearly define this comorbidity, $53.2 \%$ of people with MS and pain were above the clinical cutoff on a measure of depression (based on CES-D score), whereas 32.9\% of those with MS who did not report pain scored above the clinical cutoff, a statistically significant difference (10). Moreover, greater depressive symptomatology is associated with worse pain in persons with MS (11).

In non-MS populations, depression is associated with higher medical services utilization and costs when all healthcare treatment is considered. Depression is associated with more medical visits among primary care patients (12), back pain patients (13), and persons following stroke (14), and more medical costs among patients selected from an insurance provider $(15,16)$. Depression is also associated with both more medical visits and higher medical costs among youth with asthma (17) and the general public (18). Specific types of visits are more common among those who are depressed, including primary care, mental health, and emergency room (17); it is often stated that $60-70 \%$ of primary care visits are due to psychological distress, including depression, that is displayed through physical symptoms (19). However, among back pain patients, back pain-specific visits were not higher among depressed persons after controlling for symptom severity (20) and, similarly, among youth with asthma, total medical utilization was higher but asthma-specific visits were not higher among depressed persons (17).

The mechanism by which depression impacts treatment utilization is less clear. For example, some have reported that depressed patients often seek treatment for somatic symptoms that could be attributed to depression (21), suggesting that this excess utilization would be reduced by effective depression treatment (22). Alternatively, in the context of pain, depression is associated with greater pain-related suffering, which could subsequently motivate an individual to seek treatment to reduce this greater level of suffering. Lastly, persons with chronic pain and depressive dispositions (e.g., greater depressive symptomatology or lower optimism) experience less relief from treatments for their pain $(23,24)$ and slower recovery $(25)$, which could result in attempting more treatments before identifying a satisfactory solution.

The findings summarized regarding pain, depression, and health care utilization suggest that individuals with MS who have chronic pain and depression might be more likely to seek and obtain pain treatment than those who have chronic pain but are not depressed. If this were true, it suggests that pain-related health care costs might be lowered if depression were 
adequately assessed and treated in this population. However, we are unaware of any studies that have explored the moderating influence of depression on pain treatment utilization among persons with MS.

The primary goal of this study was to test the direct and moderating role that depression has on pain treatment in a community sample of persons with MS and chronic pain, as measured by the number of types of pain treatments currently and previously used, as well as number of visits to medical providers for pain treatment. The specific hypotheses were that: (1) individuals with depression would report more current and previous pain-related medical services utilization and (2) depression would moderate the relationship between pain intensity and pain-related medical services utilization. We did not have any a priori hypotheses about the associations between depression and specific types of pain-related medical services, as this issue has not yet been addressed in any previous study.

\section{METHODS}

\section{Procedures}

Participants for this study came from a postal survey study of pain, depression, and overall quality of life in individuals with MS. Previous data from this survey testing a motivational model of pain self-management have been reported (26). However, the present study used data not analyzed previously, with the exception of the demographics and descriptive pain intensity data. Participants were identified by randomly selecting names $(n=326)$ from a database of individuals who had previously participated in research through the University of Washington's Multiple Sclerosis Rehabilitation Research and Training. Additionally, people $(n=50)$ who contacted study staff to participate in the study (primarily from learning about the study from brochures and flyers) were also mailed surveys; surveys were mailed to five additional people obtained from other sources (clinic referrals, other UW pain studies). Inclusion criteria were 18 years of age or older and a diagnosis of MS by a medical professional. A total of 381 surveys were mailed and 161 were returned (49.0\% of 328 possible after 53 surveys were excluded: 42 because of out-of-date addresses, 5 because the potential participant was deceased, 3 because the diagnosis of MS was questionable, and 3 because they were sent a duplicate survey). Participants completing the survey were paid $\$ 25$ for their time. All study procedures were approved by the University of Washington Human Subjects Review Committee, and informed consent was obtained from each participant.

Participants included in the present analyses $(n=117)$ were those who indicated the presence of a pain problem based upon their answer to the following question: "Are you currently experiencing, or have you in the past three months experienced, any pain (other than occasional headaches or menstrual cramps)?

\section{Measures}

Demographic-The survey obtained information about participant sex, age, race/ethnicity, education level, employment status, and marital status.

Pain Intensity-Participants rated their average pain intensity during the past week on a 0 to 10 numerical rating scale (NRS), with zero indicating "no pain" and ten indicating "pain as bad as it could be." A large body of research supports the reliability and validity of the NRS for assessing pain intensity (27). NRSs are commonly used in pain research in persons with MS (2, 28-32). Moreover, 0-10 NRSs have demonstrated their validity as measures of pain intensity in persons with MS through their significant and positive associations with 
measures of pain interference $(28,32)$ and pain-related disability (28). 0-10 NRS have also demonstrated validity via their responsivity to pain treatments in persons with MS $(30,31)$.

Depression-The survey included the Patient Health Questionnaire-9 (PHQ-9; (33)) to assess depression. The PHQ-9 not only provides a reliable and valid measure of depression symptom severity but also yields a DSM-IV criteria based diagnosis of a depressive disorder (33). A commonly used cutoff for clinically significant depressive symptoms is PHQ-9 $\geq 10$, which is indicative of at least moderate depressive symptomatology with good sensitivity (0.88) and specificity (0.88) (33). In the reporting of results, we refer to those with PHQ-9 $\geq$ 10 as "depressed" and PHQ-9 < 10 as "nondepressed"; however, it is important to remember that this classification is based on established cutoffs of PHQ-9 scores and does not represent a definitive diagnosis made following a diagnostic interview. Like other populations, the measurement of depressive symptoms in persons with MS is challenged by the overlap of depressive symptoms with common medical symptoms, such as fatigue. While this may result in a greater number of depressive symptoms, previous studies reported that adjusting for somatic symptoms was not an effective approach to compensating for this measurement issue and there is a lack of consensus regarding use of revised cut-off scores in medical populations $(34,35)$; thus the PHQ-9, like any measure of depressive symptoms with medical populations, is used here with caution. Notably, the PHQ-9 has been used successfully with patients with MS in previous studies, including in a study of depressive symptoms and suicidal ideation (36).

Medical Utilization-The survey included two types of questions assessing pain treatment utilization. First, participants were asked to indicate the types of treatments they were currently using and had previously tried. Respondents selected from among 26 different pain treatments representing common pharmacologic, psychological, and physical treatments used with pain patients. (See tables 2 and 3 for complete list). Second, participants were asked to report the number of healthcare visits for pain (to primary care providers, MS specialists, other physicians, physical/occupational therapists, chiropractors, emergency department visits) during the six months prior to completing the survey.

\section{Data analysis}

We first calculated descriptive statistics for the primary study variables including patient demographics (age, sex, education, marital status, disability status), disease-related variables (duration of MS), pain (NRS for pain intensity, duration of pain symptoms), and depressive symptoms (PHQ-9 total score, percentage $\geq 10$, and percentage meeting diagnostic criteria).

We then conducted a series of analyses to test the first hypothesis regarding differences in pain treatment utilization for persons with and without depression. First, we calculated descriptive statistics for the current rates of usage of each of 26 types of pain treatments, as well as a mean total score for the number of treatments being currently used. We then conducted $\chi^{2}$ analyses to assess for differences in treatment usage based on the presence or absence of depression (PHQ-9 score 210) and a t-test to assess for group differences in the mean number of treatments used. Second, we calculated descriptive statistics for the previous usage of each of the 26 types of pain treatments, as well as a mean total score for the number of treatments previously used. We then conducted $\chi^{2}$ analyses to assess for differences in treatment usage based on the presence or absence of depression and a t-test to assess for group differences in the mean number of treatments tried. Third, we calculated descriptive statistics for the number of visits to medical providers for each of 7 types of providers as well as a mean total score for the number of visits to medical providers. Given skewed distributions, we used $\chi^{2}$ analyses to assess for differences in treatment usage based on the presence or absence of depression. T-tests were used to assess for group differences 
in the mean number of treatments used. Given that physical and occupational therapy visits occur more frequently than visits to the other providers, we also calculated a t-test for group differences in the mean number of treatments used excluding PT/OT visits.

To test our second hypothesis regarding the moderating effect of depression on the relationship of pain intensity and treatment utilization, we conducted two series of multiple regressions. To reduce any potential problems associated with multicolinearity, all variables were centered before being inputted into the model in order. The purpose of the first series of three regressions was to determine whether depression severity was associated with treatment utilization, as well as whether pain intensity was associated with treatment utilization after controlling for depression severity. In each regression, depression was entered in the first block, pain intensity was entered in the second block, and an interaction term for pain intensity and depression was entered in the third block. In the three regressions the outcome domain was treatment utilization, operationalized by (1) total number of treatments currently being used (regression one), (2) total number of treatments previously used (regression two), and (3) total number of visits to medical providers (regression three). The purpose of the second series of regressions was to determine whether pain severity was associated with treatment utilization, as well as whether depression was associated with treatment utilization after controlling for pain intensity. In each of the three regressions, pain intensity was entered in the first block, depression was entered in the second block, and an interaction term for pain intensity and depression was entered in the third block. The criterion variables in the second series of regressions were the same as those used in the first series.

\section{RESULTS \\ Demographics}

Participants were 117 persons with multiple sclerosis who experienced pain within the previous 3 months. The majority of participants were Caucasian (96.6\%) and female (83\%). Mean time since MS diagnosis was 183.50 months, and pain symptoms were experienced for a mean of 137.68 months, with mean current pain of 4.05 on the NRS (0-10), which is moderate pain severity in persons with MS (32). A majority of the sample was unemployed due to their disability $(45.3 \%)$ or pain $(6.0 \%)$ and $53.0 \%$ were currently receiving disability payments. Mean participant score on the PHQ-9 was 7.15, with 25.9\% scoring PHQ-9 $\geq 10$ and $11.1 \%$ endorsing sufficient items to meet DSM-IV criteria for a major depressive episode. Descriptive statistics are provided in Table 1.

\section{Differences in pain treatment utilization based on depression categorization}

Table 2 shows the rates of current utilization of 26 types of pain treatments by persons with depression (i.e., those who scored above the clinical cutoff of PHQ-9 $\geq 10$ in our sample) and persons without depression (PHQ-9 < 10). In total, persons with depression reported that they are currently using 4.839 types of treatment, while persons without depression reported using 4.721 treatments $(t=-0.179, n s)$. Among individual treatments, nerve blocks and TENS units were used more frequently by persons with depression relative to persons without depression.

Table 3 shows the frequency with which persons with and without depression previously tried each of 26 types of pain treatments. In total, persons with depression reported having previously tried 4.613 treatments, while persons without depression reported trying 3.477 treatments $(t=-2.641, p<0.01)$. Among individual treatments, heat, narcotics, and acetaminophen were tried more frequently by persons with depression compared to persons without depression. 
Table 4 shows the number of visits to providers for pain treatment made by persons with depression and persons without depression. In total, persons with depression reported making 15.31 visits, while persons without depression reported making 7.45 visits ( $t=$ $-1.961, p<.05)$. There were no group differences in the types of providers patients visited based upon categorically having visited the provider or not, although there was a statistical trend toward more ER visits.

Taken together, the analyses for three types of medical utilization partially support the hypothesis that depression would be associated with greater medical utilization. In support of the hypothesis, persons with depression and chronic pain had previously tried more treatments for their pain and made more visits to medical providers for pain treatment than persons without depression; however, there were no group differences in the number of treatments currently being tried.

\section{Association of depression severity and pain intensity with treatment utilization Association of pain intensity with utilization after controlling for depression severity-The results of three regressions examining the associations between pain intensity and pain treatment utilization after controlling for depression severity are presented in Table 5. The overall model for the regression analysis predicting current number of pain treatments being used was significant $(F(3,109)=3.080, p<0.05)$. In step 1 , depression was not a significant predictor and did not significantly contribute to the variance in the current number of treatments being tried. In step 2, pain intensity was a significant predictor $(\beta=0.28, p<0.01)$ and accounted for 6.9 percent of the variance in the number of treatments being tried. The direction of the association indicated that greater pain intensity was associated with currently using more treatments. In step 3, the Pain Intensity X Depression interaction did not contribute significantly to the model.}

The overall model for the regression analysis predicting number of pain treatments previously tried was significant $(F(3,109)=6.027, p<0.01)$. In step 1 , depression was a significant predictor $(\beta=0.29, p<0.01)$ and accounted for 8.5 percent of the variance in the number of treatments previously tried. The direction of the association indicated that greater depression severity was associated with having tried more treatments in the past. In step 2, pain intensity was a significant predictor $(\beta=0.24, p<0.05)$ and accounted for an additional 5.2 percent of the variance in the number of treatments previously tried. The direction of the association indicated that greater pain intensity was associated with having tried more treatments in the past. In step 3, the Pain Intensity X Depression interaction did not contribute significantly to the model.

The overall model for the regression analysis predicting number of visits to providers for pain treatment was not statistically significant $(F(3,109)=0.656, p=0.581)$. Pain intensity, depression, and the Pain Intensity X Depression interaction did not contribute significantly to the model.

\section{Association of depression severity with utilization after controlling for pain intensity-Results for three regressions predicting pain treatment utilization from} depression after controlling for pain intensity are presented in Table 6 . The overall model for the regression analysis predicting current number of pain treatments being used was significant $(F(3,109)=3.080, p<0.05)$. In step 1 , pain intensity was a significant predictor $(\beta=0.28, p<0.01)$ and accounted for 7.7 percent of the variance in the number of treatments being tried. The direction of the association indicated that greater pain intensity was associated with more current treatment modalities. In step 2, depression was not a significant predictor and did not significantly contribute to the variance in the current number of treatments being tried. Consistent with the analyses presented in the previous 
section, the Pain Intensity X Depression interaction did not contribute significantly to the model when entered in step 3 .

The overall model for the regression analysis predicting number of pain treatments previously tried was significant $(F(3,109)=6.027, p<0.01)$. In step 1 , pain intensity was a significant predictor $(\beta=0.31, p<0.01)$ and accounted for 9.5 percent of the variance in the number of treatments being tried. The direction of the association indicated that greater pain intensity was associated with have tried more treatments in the past. In step 2, depression was not a significant predictor and did not significantly contribute to the variance in the number of treatments previously tried. In step 3, the Pain intensity X Depression interaction did not contribute significantly to the model.

The overall model for the regression analysis predicting number of visits to providers for pain treatment was not significant $(F(3,109)=0.656, p=0.581)$. Pain intensity, depression, and the Pain Intensity $-\mathrm{X}$-Depression interaction did not contribute significantly to the model.

Summary-These results reveal that pain intensity, but not depression severity, is associated with the number of current treatments being used. Additionally, pain intensity is associated with the number of treatments previously used. While depression severity is also associated with the number of treatments previously used, results of the second set of analyses reveal that this association is no longer significant after controlling for pain intensity, suggesting that pain intensity mediates the association of depression with the number of treatments previously used. Across the six regressions, the results do not support the hypothesis that depression moderates the relationship between pain intensity and treatment utilization.

\section{DISCUSSION}

The present study revealed that depression is associated with greater use of some types of treatment and more frequent visits to some types of providers, but that these findings were no longer significant after controlling for pain intensity. These findings contribute to the small body of literature describing medical services utilization (5) and pain treatment utilization (Ehde et al., under review) among persons with MS and expand upon the larger body of literature on the association of depression and medical utilization in other populations $(12-18,20)$.

The results partially supported our hypothesis that depression would be associated with greater treatment utilization. Specifically, persons with depression or greater depression severity reported that they tried more pain treatments previously, with depressed patients reporting greater use of pain medications and heat relative to persons without depression. Additionally, when dichotomized into two groups, participants with depression reported that they made more visits to their medical providers for their pain. A number of potential reasons exist for this greater number of previous treatments. For example, it may be indicative of the difficulty of successfully treating pain among persons with depressed mood $(23,24)$ or that persons with depressed mood find pain less tolerable and have a greater desire to find a solution for their pain. Alternatively, given that this is cross-sectional data, the significant associations could theoretically be explained by the possibility that health care utilization itself leads to depression (i.e., that it is depressing to go to the doctor so frequently) (22). Taken together, these results are consistent with previous studies of the association of depression with medical treatment utilization in non-MS populations (12-18, 20 ) and suggest the possibility that better management of depression might result in lower 
pain treatment utilization. Research is needed to test this hypothesis using a longitudinal or experimental design.

In contrast to the first hypothesis, our second hypothesis was not supported, as depression did not moderate the pain intensity-pain treatment utilization relationship. Moreover, after controlling for pain intensity, results showed that depression no longer accounted for variation in the number of previous pain treatments utilized beyond what could be attributed to pain intensity. These findings were surprising, given that depression is associated with greater pain intensity among persons with MS (9).

While our finding that the association between depression and pain treatments became nonsignificant after controlling for pain intensity was not expected given the previous literature on depression and medical utilization (12-18), our methodology differed from past studies in important ways. The primary finding in previous studies was that depression was associated with higher utilization across all services $(12-16,18)$. Our findings are closer in methodology to two previous studies that limited their analyses to healthcare utilization for the treatment of a specific condition. In a study of low back pain patients, Engel and colleagues (20) reported that depression was associated with higher total healthcare utilization and costs, but was not associated with back pain specific healthcare utilization and costs after controlling for pain severity. Similarly, in their study of youth with asthma, Richardson and colleagues (17) reported that depression was not associated with higher utilization of asthma-specific treatment, but was associated with higher utilization of nonasthma treatment. These two studies differ from ours in that they focused on treatment of a primary condition, whereas our study considered the treatment of a secondary condition (pain) in the context of a disability (MS) that itself requires significant medical utilization. Despite this difference in focus, the finding that depression is not strongly associated with treatment for a specific problem is consistent with these other studies. This suggests that depression may remain as an important target for reducing medical utilization in the context of nonspecific medical complaints that may at least in part be somatic manifestations of depression $(19,21)$, but is less likely to impact treatment utilization for a specific complaint (e.g., pain) (20). The extent to which other factors such as depression severity and duration impacts treatment utilization is not known but worth further exploration in future studies.

The present study was limited by the use of cross-sectional data. Although these allow for an assessment of the association between depression and utilization, they do not allow for conclusions regarding causal effects. Longitudinal studies may provide better information on causality, although such studies are limited by the addition of other potential confounds over time (22). Second, the data collected were self-report. A more rigorous study design would have included a corroborating neurologist diagnosis of MS and a clinical interview for depressive symptoms. However, given the resources available for this study, such procedures would have resulted in a much smaller study population, which would have resulted in other problems, such as lower power and decreased generalizability. The methodology utilized in the present study maximized our ability to reach a larger population of persons with MS. Third, the reported rates of depressive symptoms in this study were lower than previously-reported studies and the reason for this is unclear. It may be the case that rates are lower in a community sample, such as this study, relative to clinical samples utilized in other studies. Alternatively, it is possible that nondepressed patients were more motivated - or depressed patients less motivated -- to participate in this study. Finally, there are two limitations with respect to the treatments included in this study. First, although we developed a list of treatments that we believe is representative of the available treatments for patients with MS, we recognize that there may be other pain treatments that were not included here. Second, our use of composite scores of utilization for the 26 treatments and 7 providers may have diluted some important findings, such as trends towards differences in 
utilization as a function provider type. . For example, we found a trend toward more ER visits among persons with depression, which is consistent with findings by Richardson and colleagues (17). ER visits are notoriously expensive and could result in significantly higher healthcare costs, even if the total number of visits to all providers does not vary.

\section{CONCLUSIONS}

Despite this study's limitations, the findings provide new information regarding the association of depression and medical services utilization. The results demonstrate that depression is not associated with higher pain treatment utilization, suggesting that treatment of depression may not reduce pain treatment utilization. These findings are important, as it is now the second study to recognize that depression is not associated with pain-specific treatment utilization. At the same time, it is important to recognize that by using utilization as an outcome the present study does not rule out the possibility that depression plays an important role in other aspects of treatment success. Future research should look at the role of depression in general medical services utilization for people with MS, even if painspecific utilization may not change. It will also be important to replicate and extend this study's findings by examining the effects of depression treatment on pain treatment utilization in people with MS, pain, and depression via intervention research.

\section{Acknowledgments}

Sources of Support: This research was supported by grant number P01 HD33988 from the National Institutes of Health, National Institute of Child Health and Human Development (National Center for Medical Rehabilitation Research). It was also supported in part by a grant from the National Multiple Sclerosis Society grant number MB 0008 .

\section{References}

1. Jensen MP, Moore MR, Bockow TB, Ehde DM, Engel JM. Psychosocial factors and adjustment to chronic pain in persons with physical disabilities: a systematic review. Arch Phys Med Rehabil. 2011; 92:146-60. [PubMed: 21187217]

2. Ehde DM, Osborne TL, Hanley MA, Jensen MP, Kraft GH. The scope and nature of pain in persons with multiple sclerosis. Mult Scler. 2006; 12:629-38. [PubMed: 17086910]

3. Hadjimichael O, Kerns RD, Rizzo MA, Cutter G, Vollmer T. Persistent pain and uncomfortable sensations in persons with multiple sclerosis. Pain. 2007; 127:35-41. [PubMed: 16949751]

4. Khan F, Pallant J. Chronic pain in multiple sclerosis: prevalence, characteristics, and impact on quality of life in an Australian community cohort. J Pain. 2007; 8:614-23. [PubMed: 17543586]

5. Asche CV, Singer ME, Jhaveri M, Chung H, Miller A. All-cause health care utilization and costs associated with newly diagnosed multiple sclerosis in the United States. J Manag Care Pharm. 2010; 16:703-12. [PubMed: 21067256]

6. Patten SB, Metz LM. Depression in multiple sclerosis. Psychother Psychosom. 1997; 66:286-92. [PubMed: 9403917]

7. Sadovnick AD, Remick RA, Allen J, Swartz E, Yee IM, Eisen K, et al. Depression and multiple sclerosis. Neurology. 1996; 46:628-32. [PubMed: 8618657]

8. Mohr DC, Hart SL, Julian L, Tasch ES. Screening for depression among patients with multiple sclerosis: two questions may be enough. Mult Scler. 2007; 13:215-9. [PubMed: 17439887]

9. Chwastiak L, Ehde DM, Gibbons LE, Sullivan M, Bowen JD, Kraft GH. Depressive symptoms and severity of illness in multiple sclerosis: epidemiologic study of a large community sample. Am J Psychiatry. 2002; 159:1862-8. [PubMed: 12411220]

10. Ehde DM, Gibbons LE, Chwastiak L, Bombardier CH, Sullivan MD, Kraft GH. Chronic pain in a large community sample of persons with multiple sclerosis. Mult Scler. 2003; 9:605-11. [PubMed: 14664474] 
11. Arnett PA, Barwick FH, Beeney JE. Depression in multiple sclerosis: review and theoretical proposal. J Int Neuropsychol Soc. 2008; 14:691-724. [PubMed: 18764967]

12. Katon W, Berg AO, Robins AJ, Risse S. Depression--medical utilization and somatization. West J Med. 1986; 144:564-8. [PubMed: 3716416]

13. Keeley P, Creed F, Tomenson B, Todd C, Borglin G, Dickens C. Psychosocial predictors of healthrelated quality of life and health service utilisation in people with chronic low back pain. Pain Netherlands. 2008:142-50.

14. Ghose SS, Williams LS, Swindle RW. Depression and other mental health diagnoses after stroke increase inpatient and outpatient medical utilization three years poststroke. Med Care. 2005; 43:1259-64. [PubMed: 16299438]

15. Henk HJ, Katzelnick DJ, Kobak KA, Greist JH, Jefferson JW. Medical costs attributed to depression among patients with a history of high medical expenses in a health maintenance organization. Arch Gen Psychiatry. 1996; 53:899-904. [PubMed: 8857866]

16. Simon GE, VonKorff M, Barlow W. Health care costs of primary care patients with recognized depression. Arch Gen Psychiatry. 1995; 52:850-6. [PubMed: 7575105]

17. Richardson LP, Russo JE, Lozano P, McCauley E, Katon W. The effect of comorbid anxiety and depressive disorders on health care utilization and costs among adolescents with asthma. Gen Hosp Psychiatry United States. 2008:398-406.

18. Rowan PJ, Davidson K, Campbell JA, Dobrez DG, MacLean DR. Depressive symptoms predict medical care utilization in a population-based sample. Psychol Med. 2002; 32:903-8. [PubMed: 12171384]

19. Kroenke K, Mangelsdorff AD. Common symptoms in ambulatory care: incidence, evaluation, therapy, and outcome. Am J Med. 1989; 86:262-6. [PubMed: 2919607]

20. Engel CC, von Korff M, Katon WJ. Back pain in primary care: predictors of high health-care costs. Pain. 1996; 65:197-204. [PubMed: 8826507]

21. Kirmayer LJ, Robbins JM, Dworkind M, Yaffe MJ. Somatization and the recognition of depression and anxiety in primary care. Am J Psychiatry. 1993; 150:734-41. [PubMed: 8480818]

22. Simon GE, Katzelnick DJ. Depression, use of medical services and cost-offset effects. J Psychosom Res. 1997; 42:333-44. [PubMed: 9160273]

23. Rosenberger PH, Kerns R, Jokl P, Ickovics JR. Mood and attitude predict pain outcomes following arthroscopic knee surgery. Ann Behav Med. 2009; 37:70-6. [PubMed: 19169766]

24. Achat H, Kawachi I, Spiro A, DeMolles DA, Sparrow D. Optimism and depression as predictors of physical and mental health functioning: the Normative Aging Study. Ann Behav Med. 2000; 22:127-30. [PubMed: 10962705]

25. Sullivan MJ, Adams H, Thibault P, Corbiere M, Stanish WD. Initial depression severity and the trajectory of recovery following cognitive-behavioral intervention for work disability. J Occup Rehabil. 2006; 16:63-74. [PubMed: 16670962]

26. Kratz AL, Molton IR, Jensen MP, Ehde DM, Nielson WR. Further evaluation of the motivational model of pain self-management: coping with chronic pain in multiple sclerosis. Annals of Behavioral Medicine. 2011; 41:391-400. [PubMed: 21213092]

27. Jensen, MP.; Karoly, P. Self-report scales and procedures for assessing pain in adults. In: Turk, DC.; Melzack, R., editors. Handbook of pain assessment. New York: Guilford Press; 2011.

28. Osborne TL, Raichle KA, Jensen MP, Ehde DM, Kraft G. The reliability and validity of pain interference measures in persons with multiple sclerosis. J Pain Symptom Manage. 2006; 32:21729. [PubMed: 16939846]

29. Osborne TL, Jensen MP, Ehde DM, Hanley MA, Kraft G. Psychosocial factors associated with pain intensity, pain-related interference, and psychological functioning in persons with multiple sclerosis and pain. Pain. 2007; 127:52-62. [PubMed: 16950570]

30. Jensen MP, Barber J, Romano JM, Molton IR, Raichle KA, Osborne TL, et al. A comparison of self-hypnosis versus progressive muscle relaxation in patients with multiple sclerosis and chronic pain. Int J Clin Exp Hypn. 2009; 57:198-221. [PubMed: 19234967]

31. Jensen MP, Ehde DM, Gertz KJ, Stoelb BL, Dillworth TM, Hirsh AT, et al. Effects of selfhypnosis training and cognitive restructuring on daily pain intensity and catastrophizing in 
individuals with multiple sclerosis and chronic pain. Int J Clin Exp Hypn. 2011; 59:45-63. [PubMed: 21104484]

32. Alschuler KN, Jensen MP, Ehde DM. Defining mild, moderate, and severe pain in persons with multiple sclerosis. Pain Medicine. In press.

33. Kroenke K, Spitzer RL, Williams JB. The PHQ-9: validity of a brief depression severity measure. J Gen Intern Med. 2001; 16:606-13. [PubMed: 11556941]

34. Turk DC, Okifuji A. Detecting depression in chronic pain patients: adequacy of self-reports. Behav Res Ther. 1994; 32:9-16. [PubMed: 8135727]

35. Geisser ME, Roth RS, Robinson ME. Assessing depression among persons with chronic pain using the Center for Epidemiological Studies-Depression Scale and the Beck Depression Inventory: a comparative analysis. Clin J Pain. 1997; 13:163-70. [PubMed: 9186024]

36. Turner AP, Williams RM, Bowen JD, Kivlahan DR, Haselkorn JK. Suicidal ideation in multiple sclerosis. Arch Phys Med Rehabil. 2006; 87:1073-8. [PubMed: 16876552] 
Table 1

Descriptive statistics for demographics and variables related to MS, pain, and depression

\begin{tabular}{|c|c|}
\hline & Mean (SD) or \% \\
\hline Age & $54.02(11.86)$ \\
\hline \multicolumn{2}{|l|}{ Sex } \\
\hline Male & $17 \%$ \\
\hline Female & $83 \%$ \\
\hline \multicolumn{2}{|l|}{ Education } \\
\hline Completed grades 10-11 (some high school) & $0.9 \%$ \\
\hline High school graduate or GED & $9.4 \%$ \\
\hline Vocational or technical school & $7.7 \%$ \\
\hline Some college & $23.1 \%$ \\
\hline College graduate & $38.5 \%$ \\
\hline Graduate school or professional school & $20.5 \%$ \\
\hline \multicolumn{2}{|l|}{ Employment } \\
\hline Employed full-time & $20.5 \%$ \\
\hline Employed part-time & $7.7 \%$ \\
\hline Attending school or vocational training full-time & $0 \%$ \\
\hline Attending school or vocational training part-time & $0 \%$ \\
\hline Retired & $29.1 \%$ \\
\hline Homemaker & $11.1 \%$ \\
\hline Unemployed due to pain & $6.0 \%$ \\
\hline Unemployed due to disability & $45.3 \%$ \\
\hline Unemployed for other reasons & $2.6 \%$ \\
\hline \multicolumn{2}{|l|}{ Ethnicity } \\
\hline African-American & $0.9 \%$ \\
\hline Asian & $1.7 \%$ \\
\hline Caucasian (white) & $96.6 \%$ \\
\hline Hispanic/Chicano & $0.0 \%$ \\
\hline Native American/American Indian/Alaskan Native & $2.6 \%$ \\
\hline Pacific Islander & $0.9 \%$ \\
\hline Other & $0.0 \%$ \\
\hline Receiving disability & $53.0 \%$ \\
\hline \multicolumn{2}{|l|}{ Marital status } \\
\hline Married & $58.1 \%$ \\
\hline Separated & $3.4 \%$ \\
\hline Divorced & $19.7 \%$ \\
\hline Living with significant other & $4.3 \%$ \\
\hline Never married & $7.7 \%$ \\
\hline Widowed & $6.8 \%$ \\
\hline Duration of MS (months) & $183.50(119.66)$ \\
\hline Duration of MS-related pain (months) & $137.68(120.59)$ \\
\hline
\end{tabular}




\begin{tabular}{|c|c|}
\hline & Mean (SD) or \% \\
\hline Pain over past week & \\
\hline NRS $(0-10)$ & $4.05(2.68)$ \\
\hline Depressive symptoms & \\
\hline PHQ-9 total score & $7.15(5.53)$ \\
\hline PHQ-9 diagnostic criteria & $11.1 \%$ \\
\hline PHQ-9 $\geq 10$ & $25.89 \%$ \\
\hline
\end{tabular}


Table 2

Treatments patients are current using for their pain

\begin{tabular}{|c|c|c|c|}
\hline Treatments currently using for pain $(\%(\mathrm{~N}))$ & Depressed (PHQ-9 $\geq 10$ ) & Non-depressed (PHQ-9 < 10) & $\chi^{2}$ \\
\hline Physical therapy & $45.2 \%(14)$ & $44.2 \%(38)$ & 0.009 \\
\hline Nerve blocks & $9.7 \%(3)$ & $1.2 \%(1)$ & $5.003^{*}$ \\
\hline Biofeedback/relaxation & $9.7 \%(3)$ & $4.7 \%(4)$ & 1.023 \\
\hline Acupuncture & $16.1 \%(5)$ & $17.4 \%(15)$ & 0.028 \\
\hline Magnets & $9.7 \%(3)$ & $11.6 \%(10)$ & 0.088 \\
\hline Massage & $45.2 \%(14)$ & $39.5 \%(34)$ & 0.298 \\
\hline Hypnosis & $3.2 \%(1)$ & $2.3 \%(2)$ & 0.074 \\
\hline Counseling/psychotherapy & $19.4 \%(6)$ & $14.0 \%(12)$ & 0.511 \\
\hline Mexiletine & $0.0 \%(0)$ & $0.0 \%(0)$ & None \\
\hline Neurontin & $22.6 \%(7)$ & $16.3 \%(14)$ & 0.614 \\
\hline TCAs & $12.9 \%(4)$ & $18.6 \%(16)$ & 0.523 \\
\hline Narcotics & $25.8 \%(8)$ & $30.2 \%(26)$ & 0.217 \\
\hline Acetaminophen & $29.0 \%(9)$ & $39.5 \%(34)$ & 1.081 \\
\hline Advil, aspirin, aleve & $19.4 \%(6)$ & $32.6 \%(28)$ & 1.927 \\
\hline Diazepam, alprazolam & $9.7 \%(3)$ & $16.3 \%(14)$ & 0.800 \\
\hline Tegretol & $9.7 \%(3)$ & $8.1 \%(7)$ & 0.069 \\
\hline Baclofen & $22.6 \%(7)$ & $19.8 \%(17)$ & 0.111 \\
\hline TENS unit & $25.8 \%(8)$ & $9.3 \%(8)$ & $5.258^{*}$ \\
\hline Dilantin or other anticonvulsant & $0.0 \%(0)$ & $2.3 \%(2)$ & 0.733 \\
\hline Chriopractic adjustment & $22.6 \%(7)$ & $23.3 \%(20)$ & 0.066 \\
\hline Heat & $29.0 \%(9)$ & $30.2 \%(26)$ & 0.016 \\
\hline Ice & $41.9 \%(13)$ & $38.4 \%(33)$ & 0.121 \\
\hline Marijuana & $9.7 \%(3)$ & $5.8 \%(5)$ & 0.534 \\
\hline Strengthening exercises & $16.1 \%(5)$ & $23.3 \%(20)$ & 0.689 \\
\hline Mobility exercises or ROM & $16.1 \%(5)$ & $14.0 \%(12)$ & 0.087 \\
\hline Implanted nerve stimulator & $12.9 \%(4)$ & $9.3 \%(8)$ & 0.321 \\
\hline Implanted medication pump & $0.0 \%(0)$ & $0.0 \%(0)$ & None \\
\hline Total number of current treatments ${ }^{a}$ & $4.839(2.672)$ & $4.721(3.282)$ & -0.179 \\
\hline \multicolumn{4}{|l|}{ Note. } \\
\hline \multicolumn{4}{|l|}{${ }^{*} p<0.05$} \\
\hline \multicolumn{4}{|l|}{${ }^{* *} \quad p<0.01$} \\
\hline$* * * * 0.001$. & & & \\
\hline
\end{tabular}


Table 3

Treatments patients previously used for their pain

\begin{tabular}{|c|c|c|c|}
\hline Treatments previously used for pain $(\%(\mathrm{~N}))$ & Depressed (PHQ-9 $\geq 10)$ & Non-depressed (PHQ-9 < 10) & $\chi^{2}$ \\
\hline Physical therapy & $12.9 \%(4)$ & $12.8 \%(11)$ & 0.000 \\
\hline Nerve blocks & $0.0 \%(0)$ & $0.0 \%(0)$ & None \\
\hline Biofeedback/relaxation & $0.0 \%(0)$ & $1.2 \%(1)$ & 0.364 \\
\hline Acupuncture & $3.2 \%(1)$ & $1.2 \%(1)$ & 0.577 \\
\hline Magnets & $0.0 \%(0)$ & $1.2 \%(1)$ & 0.364 \\
\hline Massage & $3.2 \%(1)$ & $10.5 \%(9)$ & 1.528 \\
\hline Hypnosis & $0.0 \%(0)$ & $0.0 \%(0)$ & None \\
\hline Counseling/psychotherapy & $6.5 \%(2)$ & $1.2 \%(1)$ & 2.551 \\
\hline Mexiletine & $0.0 \%(0)$ & $0.0 \%(0)$ & None \\
\hline Neurontin & $19.4 \%(6)$ & $17.4 \%(15)$ & 0.057 \\
\hline TCAs & $3.2 \%(1)$ & $3.5 \%(3)$ & 0.005 \\
\hline Narcotics & $38.7 \%(12)$ & $17.4 \%(15)$ & $5.806^{*}$ \\
\hline Acetaminophen & $54.8 \%(17)$ & $31.4 \%(27)$ & $5.337^{*}$ \\
\hline Advil, aspirin, aleve & $61.3 \%(19)$ & $48.8 \%(42)$ & 1.416 \\
\hline Diazepam, alprazolam & $3.2 \%(1)$ & $11.6 \%(10)$ & 1.889 \\
\hline Tegretol & $6.5 \%(2)$ & $2.3 \%(2)$ & 1.175 \\
\hline Baclofen & $25.8 \%(8)$ & $32.6 \%(28)$ & 0.488 \\
\hline TENS unit & $0.0 \%(0)$ & $3.5 \%(3)$ & 1.110 \\
\hline Dilantin or other anticonvulsant & $6.5 \%(2)$ & $1.2 \%(1)$ & 2.551 \\
\hline Chriopractic adjustment & $9.7 \%(3)$ & $8.1 \%(7)$ & 0.069 \\
\hline Heat & $45.2 \%(14)$ & $14.0 \%(12)$ & $12.840^{* * *}$ \\
\hline Ice & $29.0 \%(9)$ & $14.0 \%(12)$ & 3.518 \\
\hline Marijuana & $19.4 \%(6)$ & $5.8 \%(5)$ & 4.905 \\
\hline Strengthening exercises & $54.8 \%(17)$ & $48.8 \%(42)$ & 0.328 \\
\hline Mobility exercises or ROM & $45.2 \%(14)$ & $34.9 \%(30)$ & 1.026 \\
\hline Implanted nerve stimulator & $12.9 \%(4)$ & $20.9 \%(18)$ & 0.962 \\
\hline Implanted medication pump & $0.0 \%(0)$ & $3.5 \%(3)$ & 1.110 \\
\hline Total number of previous treatments ${ }^{a}$ & $4.613(2.290)$ & $3.477(1.963)$ & $-2.641^{* *}$ \\
\hline \multicolumn{4}{|l|}{ Note. } \\
\hline \multicolumn{4}{|l|}{$* x<0.05$} \\
\hline \multicolumn{4}{|l|}{${ }^{* *}<0.01$} \\
\hline 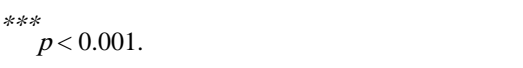 & & & \\
\hline
\end{tabular}




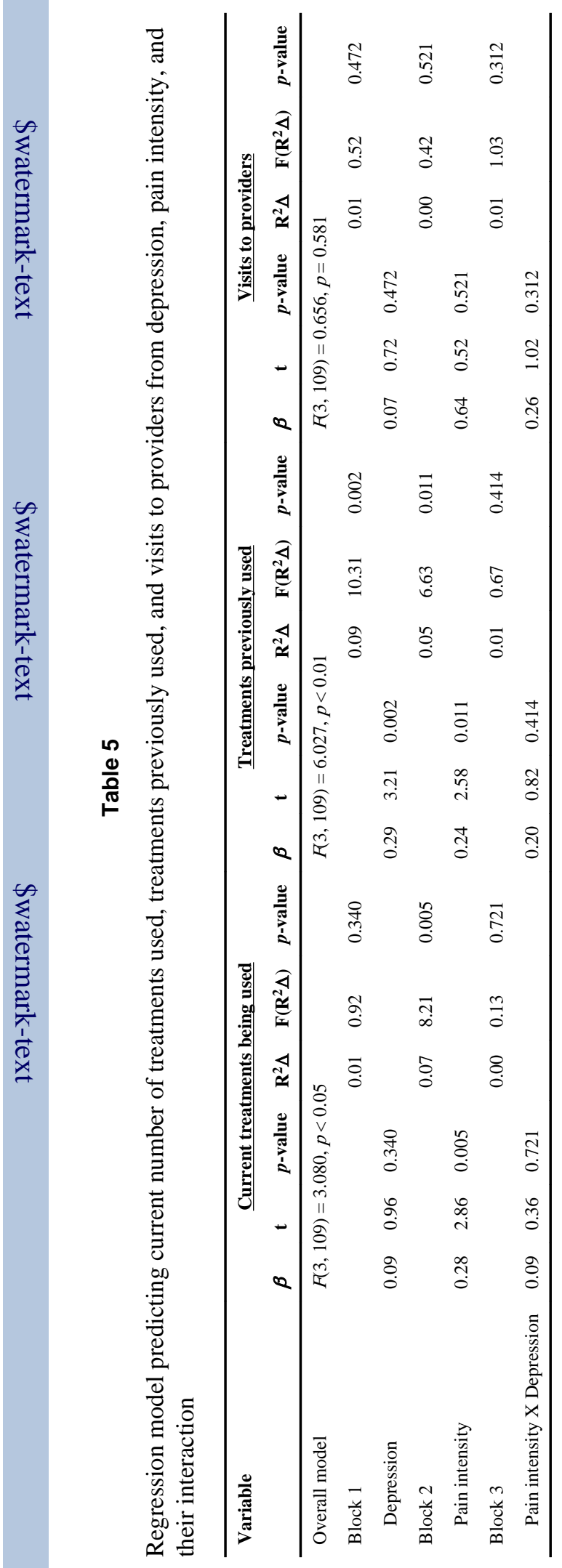

Pain Med. Author manuscript; available in PMC 2013 December 01. 


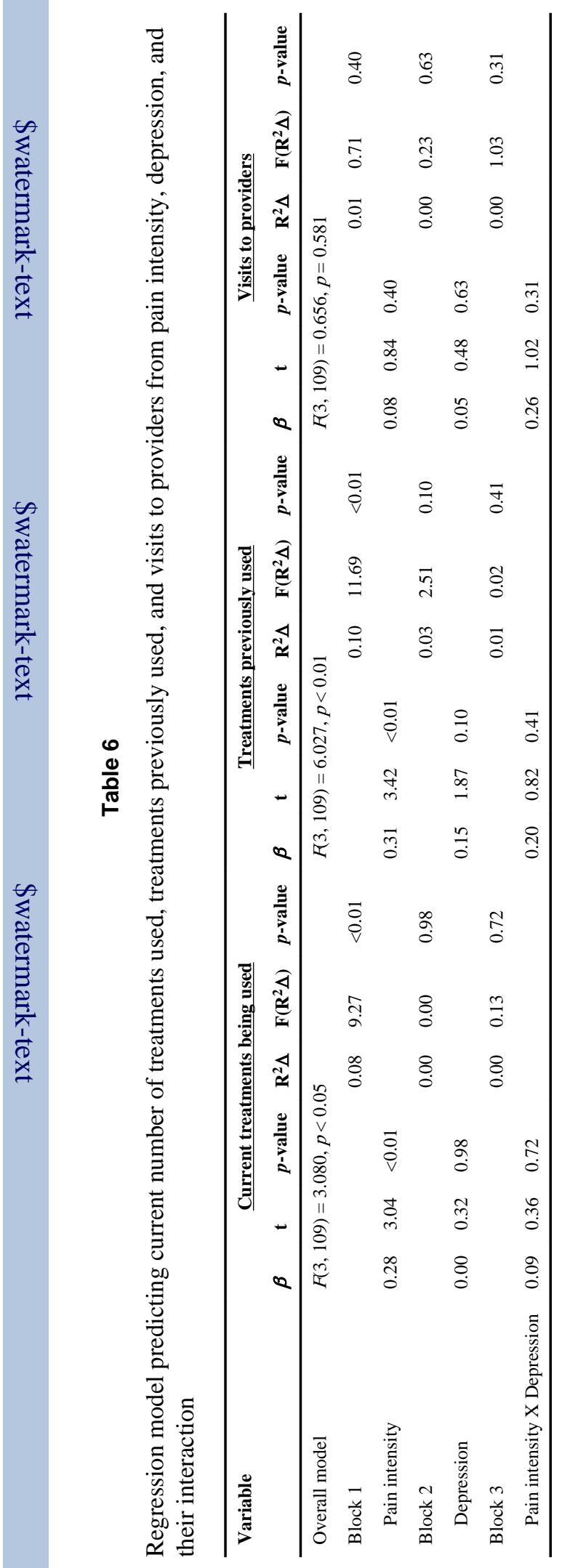

Pain Med. Author manuscript; available in PMC 2013 December 01. 